\title{
Health Literacy Among Long-Term Breast Cancer Survivors; Exploring Associated Factors in a Nation- Wide Sample
}

Kathrine Vandraas ( $\square$ katvan@ous-hf.no)

Oslo University Hospital: Oslo Universitetssykehus https://orcid.org/0000-0002-6093-3385

Kristin Valborg Reinertsen

Oslo University Hospital: Oslo Universitetssykehus

Cecilie Kiserud

Oslo University Hospital: Oslo Universitetssykehus

Synne Bøhn

Oslo University Hospital: Oslo Universitetssykehus

Hanne Cathrine Lie

University of Oslo: Universitetet i Oslo

\section{Research Article}

Keywords: health literacy, breast cancer survivorship, neuroticism, fear of cancer recurrence

Posted Date: January 18th, 2022

DOI: https://doi.org/10.21203/rs.3.rs-1178066/v1

License: (c) (1) This work is licensed under a Creative Commons Attribution 4.0 International License. Read Full License 


\section{Abstract \\ Background}

Poor health literacy $(\mathrm{HL})$ likely hampers health management and outcomes in cancer survivorship. Knowledge of associated factors is needed to identify at-risk sub-groups of survivors, but is currently scant. Here, we explore HL and associated factors in a nation-wide sample of long-term breast cancer survivors (BCSs).

\section{Material and methods}

All BCSs aged 20-65 years, diagnosed with early-stage BC in 2011-2012, were identified through the Norwegian Cancer Registry and invited to participate in the Survivorship, Work and Sex (SWEET)-study. HL was measured using The European Health Literacy Survey Questionnaire-12 (HLS-EU-Q12) as a continuous and categorical variable. Associations between $\mathrm{HL}$ and sociodemographic-, physical- and mental health variables, including the most common late effects, were explored in uni- and multivariable linear regression models.

\section{Results}

The final sample consisted of 1355 survivors (48\%). Median age was 60 years and the majority of survivors had high socioeconomic status (SES). Median HL sum-score corresponded to an intermediate HL level (36.2, SD 5.4), while 19.3\% reported marginal or inadequate HL. Education, income, age at diagnosis, the personality trait neuroticism and fear of cancer recurrence (FCR) remained significantly associated with $\mathrm{HL}$ in the multivariate model, explaining $12 \%$ of the variance in $\mathrm{HL}$ scores.

\section{Conclusion}

Low levels of HL were prevalent, potentially affecting the provision of effective survivorship care and BCS's self-management abilities. Identifying individuals at risk of low HL based on knowledge readily available to clinicians remains challenging and warrants further investigation.

\section{Background}

Health literacy $(\mathrm{HL})$; the ability to access, understand, appraise and apply health information [1], effect long term health outcomes [2,3]. Within various chronic conditions, individuals with low HL are reported to have higher mortality, more frequent use of health care services and reduced quality of life compared to individuals with high $\mathrm{HL}[4,5]$. Almost 1 in 2 Europeans are reported to have limited $\mathrm{HL}$, but there are extensive variations in prevalence likely reflecting a social gradient $[2,6]$. $\mathrm{HL}$ is especially relevant in an oncological setting given the sheer complexity of diagnostics and treatments, and the expectations of 
active patient involvement [7]. Despite the importance of sound knowledge of HL in oncology, research is limited compared to other major illnesses, especially within subgroups of patients [8].

Self-management encompasses individuals' ability to monitor their condition and manage cognitive, behavioral and emotional responses to preserve quality of life (QOL) [9], and has been identified as a possible mediator between $\mathrm{HL}$ and poor health outcomes [10]. Low HL and inefficient self-management skills are associated with increasing symptom burden [11] highlighting the importance of such skills for cancer survivorship. A recent study on head and neck cancer survivors reported lower levels of selfmanagement behaviors and health related quality of life among survivors with low HL compared to individuals with high $\mathrm{HL}$ [12].

Early stage BC has excellent long term prognosis with 5-year survival rates above $90 \%$ in the Western World [13], resulting in a rapidly increasing population of BC survivors (BCSs). Survivorship is characterized by substantial uncertainty due to risks of cancer recurrence and treatment related late effects (LEs), such as fatigue, cognitive dysfunction, mental health problems, sleep disturbances, neuropathy and pain $[14,15]$. To mitigate these risks survivors are recommended to adhere to a healthy life style and follow-up guidelines. As such, cancer survivorship resembles that of other chronic diseases, including type II diabetes, where effective self-management is associated with improved health outcomes [4].

Among BC patients low HL appears to be prevalent with estimates varying between $50-90 \%$, with highest estimates among elderly and in lower socioeconomic groups $[16,17]$. BCSs with low HL report more fear of cancer recurrence (FCR) [16], a higher degree of unmet informational and supportive care needs [18], and lower health-related QoL compared to BCSs with high HL [11]. However, we lack in depth knowledge of HL among long-term BCSs, with specific attention to survivors dealing with LEs.

Increasing $\mathrm{HL}$ and thereby self-management is a potentially potent pathway for improving long term health outcomes among BCSs. In order to succeed we need to be able to identify individuals at risk. The aims of this study are to describe HL in a large, nation-wide cohort of long term BCSs and to explore factors associated with low HL, including the most prevalent physical and mental LEs.

\section{Material And Methods}

\section{Sampling}

All Norwegian female BCSs within working age (20-65 years) with early-stage BC (stage I-III) in 20112012, were invited to the participate in the Survivorship, Work and Sexual Health (SWEET)-study, in total 2803 women. Survivors were identified through the Cancer Registry of Norway (CRN) which is based on mandatory reporting, yielding close to complete prevalence estimates [19]. BCSs had to be free of prior or successive malignant disease in order to be included, with the exception of survivors diagnosed with nonmelanoma skin cancer or ductal carcinoma in situ (DCIS) in addition to their invasive BC. One reminder was sent to BCSs who did not respond to the first invitation $(n=1684)$. 


\section{Primary outcome}

$H L$ was self-reported using The European Health Literacy Survey Questionnaire-12 (HLS-Q12), a shortversion of the validated HLS-Q47. The short-version consist of 12 items which measure HL across the four cognitive domains (access, understand, appraise and apply health information) and the three health contexts (health care, disease prevention and health promotion) capturing the multidimensionality of HL as proposed in the HLS-Q47 [1]. The HLS-Q12 is reported to be a valid screening tool for HL in a clinical setting, and has been validated in the Norwegian population [20]. Answers to each item are given on a 4point rating scale from very difficult to very easy, resulting in a sum score from 12 to 48 , where a higher score reflects higher levels of HL. In addition, a "don't know"-category is included for each item [20]. "Don't know"- responses and missing values were imputed with mean score of all items, if more than $80 \%$ of items were completed.

In addition to the sum score, HL-values were categorized into four levels based on previously defined thresholds; inadequate ( 12 to 26 points), marginal ( 27 to 32 points), intermediate (33 to 38 points) and advanced HL (39 to 48 points) [21] .

\section{Variables}

\section{Self-reported}

Sociodemographic variables: living arrangements were categorized as living with a partner or children or not. Education was first dichotomized into higher and lower education ( $>12$ years/ $\leq 12$ years), before further stratifying the first group into $\geq 4$ years or $<4$ years of higher education, in order to identify respondents with a university degree. High household income was defined as $\geq 500.000$ NOK per year during the year prior to survey, corresponding to approximately $\geq 48000 €$ per year. Employment included full time work, part time work, self-employment and workers on sick leave.

Physical health: the presence of somatic comorbidity was based on a modified version of the Charlson co-morbidity index, which includes 17 questions on major organ system disease (coronary-, pulmonary-, gastrointestinal-, kidney-, neurological-, rheumatic- and musculoskeletal- disorders) [22, 23]. Affirmative responses were categorized into 1-2 conditions or $>2$ conditions.

The personality trait neuroticism was assessed using a short version of the Eysenck Personality Questionnaire (EPQ), which includes six items rated as present (1) or absent (0), resulting in a sum score range from 0-6, before being dichotomized into high (sum score 3-6) and low neuroticism (sum score 0-2) according to established procedures [24]. Missing values were substituted with mean values for that item from the over-all sample when more than $50 \%$ of items had been answered. Cronbach's alpha was 0.8 .

\section{Cancer related characteristics}

Age at diagnosis, pathological stage, hormone receptor- and HER-2 status and information on surgical treatment were obtained from the CRN. Additional treatment information was based on self-report. 
Treatment was classified in five groups; surgery, chemotherapy, radiotherapy, endocrine treatment and Herceptin.

\section{Possible late effects after breast cancer}

Pain intensity and cognitive function was assessed using the European Organization for Research and Treatment of Cancer quality of life questionnaire (EORTC- QLQ - C30 version 3) [25]. Responses on each item were given on a 4-point scale ranging from 1 (not at all) to 4 (very much) before transforming, as recommended by EORTC, each scale into a 0-100 point scale. A higher pain score reflects higher symptom intensity. For cognitive function a higher score reflects a higher level of functioning. Cronbach's alpha for the EORTC- QLQ - C30 was 0.9.

Neuropathy was self-rated using the scale for chemotherapy induced long-term neurotoxicity (SCIN) [26] rating the presence of neuropathy in hands and feet on a scale from 0 (not at all) to 3 (very much) through two items, before dichotomizing the sum score to high $(\geq 4)$ or low $(\leq 3)$ degree of neuropathy.

Arm and breast symptoms were assessed using the European Organization for Research and Treatment of Cancer Breast Cancer -Specific Quality of Life Questionnaire Module (EORTC QLQ-BR23 questionnaire). Responses are given on a 4-point scale ranging from 1 (not at all) to 4 (very much), before being transformed into a 0-100 point scale where higher symptom score reflects higher symptom intensity [27]. Cronbach's alpha for the BR23 was 0.8 .

Fatigue was measured using Chalder's Fatigue Questionnaire, which measure symptoms of fatigue through 11 items; seven items on physical fatigue and four items on mental fatigue. Response alternatives are given on a 4-point Likert scale from 0-3, yielding a total fatigue score ranging from 0 to $33[28]$. A higher score indicates higher symptom intensity. Cronbach's alpha was 0.9 .

Using two items from the Nord-Trøndelag Health Study (the HUNT-study) [29], sleep problems were defined as more than three episodes per week of difficulty falling asleep and/or waking up too early without being able to go back to sleep, over the past 3 months. Responses were dichotomized into "yes" (often or almost every night) and "no" (never or occasionally).

Depressive symptoms was measured using The Patient Health Questionnaire-9 (PHQ-9) [30], which corresponds to the nine DSM-IV diagnostic criteria for depressive disorders and measures symptom severity during the past two weeks, rated on a four-point scale from 0 (not at all) to 3 (nearly every day). The sum-score ranges from 0 to 27 , with a higher score indicating higher symptom severity. Cronbach's alpha was 0.8 .

Anxiety symptoms was evaluated using the General Anxiety Disorder 7-item scale (GAD-7) [31], which consists of seven items measuring symptom intensity during the last two weeks. Response categories range from not at all (0) to nearly every day (3), giving a sum score ranging from $0-21$. Cronbach's alpha was 0.9 . 
FCR was measured using four items from the Concern About Recurrence Questionnaire (CARQ) [32]. The first three items assess the frequency and degree of FCR, with responses rated on an 11-point scale from 0 (not at all) to 10 (a great deal). The fourth item asks respondents to rate self-perceived risk of recurrence from $0-100 \%$. Scoring on item 4 is transformed to the same rating scale as the other three items, and a sum score is calculated, ranging from 0-40. Cronbach's alpha was 0.7.

\section{Statistical analyses}

Descriptive statistics was performed for the sample in total. For the $\mathrm{HL}$ variable, response frequencies across the 12 items of the HLS-Q12, in total and within each response category, were performed, before analyzing $\mathrm{HL}$ both as a categorical and continuous variable. Mean scores for $\mathrm{HL}$ based on imputed and original values were calculated. Univariate linear regression with $\mathrm{HL}$ as the dependent variable was carried out, and all statistically significant associations ( $p$-value $\leq 0.1$ ), were incorporated into a multivariate linear model. Survivors with one or more missing values on any of the included variables were excluded from the regression analyses. IBM SPSS statistics version 26 (SPSS, Chicago, IL) was used for all analyses.

\section{Results}

In total, 1361 BCSs returned the questionnaire (49\% response rate) among whom three were excluded due to incomplete consent, and three due to self-reported BC recurrence. The final sample included 1355 (48\%) BCSs. Mean age at time of survey was close to 60 years (59.9 years, SD 8.7), and on average eight years had passed since diagnosis. More than half had higher education (51\%), including $30 \%$ who had more than 4 years of higher education. Sixty eight \% had a high household income. At time of diagnosis, $3 / 4$ of the survivors were employed (76.4\%). Most had undergone surgical treatment (99.5\%), and close to $68 \%$ had received chemotherapy. Almost $80 \%$ reported at least one co-morbid condition (78\%). Sleep problems were present among $44 \%$ and $20 \%$ reported a high degree of neuropathy (Table 1 ).

The mean $\mathrm{HL}$ sum scores, both before and after imputation procedures, corresponded to intermediate $\mathrm{HL}$ levels (36.4 (SD 5.5) and 36.2 (SD 5.4) respectively). HL scores in the inadequate or marginal range were reported among $19.3 \%$. The $\mathrm{HL}$ item concerning the ability to judge the advantages and disadvantages of different treatment options had the lowest scores, rated as difficult or very difficult by $41.1 \%$, followed by the item assessing the ability to judge if information on health risk in the media is reliable (35.3\%). In contrast, the items on ability to follow written instructions on medications and to understand why health screening is important were reported to be easy or very easy by $91.7 \%$ and $93.8 \%$ respectively (Table 2 ).

In the univariate analyses, $\mathrm{HL}$ was associated with educational attainment $(B=2.4, p<0.01)$, age at survey $(B=-0.07, p<0.01)$ and income $(B=2.2, p<0.01)$. Employment was inversely associated with $\mathrm{HL}$ $(B=-1.2, p 0.01)$, as was neuroticism $(B=-0.67, p<0.01)$. The only cancer related variables associated with $H L$ was hormone receptor positivity $(B=-1.2, p 0.01)$ and age at diagnosis $(B=-0.07, p<0.01)$. Comorbidity $(B=-1.48, p<0.01)$ and all late effects (pain; $B=-0.02$, $p$-value $>0.01$, breast symptoms; $B=$ $-0.04, p<0.01$, arm symptoms; $B=-0.03, p<0.01$, neuropathy; $B=-0.87, p 0.04$, sleep problems; $B=-0.67, p$ 
$<0.01$, fatigue; $B=-0.11, p<0.01$, depressive symptoms; $B=-0.21, p<0.01$, anxiety symptoms; $B=-0.32, p$ $<0.01$ and fear of cancer recurrence; $B=-0.15, p<0.01$ ) were inversely associated with $H L$, except for cognitive function which was positively associated with $\mathrm{HL}(B=0.03, p<0.01)$ (Table 3$)$.

In multivariate analyses, $\mathrm{HL}$ was significantly associated with more than 4 years of higher education ( $B$ $=1.32, p<0.01)$, age at diagnosis $(B=-0.08, p<0.01)$ and income $(B=1.1, p 0.01)$. Other socioeconomic variables were no longer significantly associated with $\mathrm{HL}$. FCR and neuroticism remained inversely associated with $\mathrm{HL}(B=-0.08, p<0.01$, and $B=-0.27, p 0.03$ respectively). All other late effects were nonsignificant in the adjusted analyses. The included explanatory variables collectively explained $12 \%$ of the variance in $\mathrm{HL}\left(\mathrm{R}^{2}\right.$ adj 0.12$)$ (Table 4$)$. Age at survey was not included in the analysis due to high collinearity with age at diagnosis.

The non-responders were significantly older (53.2 years at diagnosis versus 51.9 years), a larger proportion was lymph node- (64\% versus $60 \%$ ) and Her2 -negative ( $80 \%$ versus $76 \%$ ) and Ki67 was lower (mean 27 versus 31). There were no significant differences in tumor size, hormone receptor status or type of surgery between responders and non-responders (results not shown).

\section{Discussion}

One in five long-term BCSs had HL levels in the marginal or inadequate range. $\mathrm{HL}$ at this level likely limits the ability to understand and make use of health related information and engage in effective selfmanagement, which are key aspects of successful cancer survivorship.

Three HL-items were labelled as easy or very easy by $90 \%$ or more of the sample, reflecting a high degree of more basic or functional HL skills, such as following written instructions. However, 35-41\% reported difficulty with advanced $\mathrm{HL}$ tasks, such as complex judgment calls regarding treatment and health risks, which reflect the cognitive domain "appraisal" in the original HL framework [1]. These findings support the theory that $\mathrm{HL}$ is as a multi-dimensional concept which may vary across health-related contexts. This is in line with other studies, including the European Health Literacy survey (HLS-EU), where items reflecting more advanced, critical HL skills were experienced as the most difficult $[6,33]$. In the HLS-EU, HL was as expected highest in Western European countries, but with substantial variations related to age, health and socioeconomic status [6]. BC risk is positively associated with high socioeconomic status, and the majority of BCSs in this survey had high SES. This may account for the relatively high mean HL score. The most critical HL skills for cancer survivorship may still be lacking for a substantial proportion of survivors. In line with previous findings, we observed an association between lower HL and increasing age $[12,16]$. Old age involves declining sensory and cognitive functioning which may affect HL skills directly. Additionally, with age the risk of comorbidity also increases. Multi-morbid, more fragile patients report lower HL when faced with cancer than patients with higher performance status [11], possibly because they already engage in complex self-management behaviors. Dealing with cancer in this context may exceed their overall coping capacity. BCSs of older age may therefore represent a particularly vulnerable group with regards to the effects of low HL. 
FCR, the persistent fear or worry that the cancer will return or progress [34], is a frequent concern among BCSs [35], shown to persist over time, also among survivors with favorable long-term prognosis, such as $B C$ [36]. In the present study, FCR was the only late effect that remained significantly associated with HL in the adjusted model. Our finding is in line with results presented by Halbach et al who concluded that limited HL is an independent risk factor for higher levels of FCR [16]. Low HL may impact the risk of FCR through different mechanisms, such as reduced ability to navigate, critically assess, understand and handle health related information, but also through sub-optimal interaction with health care providers, for instance through avoidance behavior. Among cancer patients, low HL has been associated with lower perceived information provision and information satisfaction compared to higher $\mathrm{HL}$ [37]. Combined, low $\mathrm{HL}$ may result in unmet informational and supportive care needs and perhaps unnecessarily high levels of FCR, as demonstrated in previous studies [18].

In an oncological setting, neuroticism, the propensity for negative emotions when faced with negative stress, has been associated with reduced quality of life and increased risk of post-traumatic stress disorder following cancer [38]. Neuroticism may affect self-management behaviors, as reported for patients with other chronic diseases such as diabetes [39], thereby linking it to HL-skills. Although research is limited, low HL has been associated with neuroticism [40]. We observed the same association, which remained stable in the adjusted analyses. We have not been able to find other studies specifically exploring $\mathrm{HL}$ and neuroticism among BCSs warranting further investigations. Our finding implies that specific personality characteristics may indicate poorer HL-skills. Such knowledge may be valuable in a clinical setting making it easier for clinicians to identify individuals at risk of poorer outcomes.

As symptom burden and functional limitations increase, self-perceived HL and self-management seem to decline [11]. Following this line of reasoning, individuals with low HL may be particularly vulnerable when faced with treatment related late effects. This was not the case in the present sample. This may be due to the survivors' relatively high $\mathrm{HL}$ levels, enabling them to handle these stressors, or that increasing demands in fact has stimulated HL skills over time. It is also possible that HL is more clearly linked to late effects during the first years of cancer survivorship, before effective coping strategies are in place and the emotional distress is likely to be higher. Exploring HL among BC patients living with advanced disease will be interesting for further studies.

\section{Strengths and limitations}

BCSs in this study were recruited from an unselected, unbiased population. All long-term, early-stage BCSs diagnosed with $B C$ within working age registered in the CRN were invited to participate, granting us with a large sample of high quality.

Given the inclusion criteria for the present study, non-responders did not differ according to diagnosis (early-stage $\mathrm{BC}$ ), gender or time of diagnosis. Additional clinical data from the CRN concerning cancerrelated variables revealed only slight differences between responders and non-responders. We cannot exclude the possibility that non-responders differ according to other variables, such as ethnic background 
and $\mathrm{HL}$ skills, as reading and understanding Norwegian was necessary in order to complete the questionnaire. However, data use restrictions prohibited us from performing complete analyses of the non-responders. Although declining response rates in health surveys in general may threaten external validity, a response rate of $49 \%$ is considered acceptable and comparable to other large-scale surveys on long-term cancer survivors in Norway [41]. Furthermore, in comparable survey-studies, with more modest response rates than reported here, evidence of response bias was not found [42].

This sample reflects the Norwegian BCS population, which is quite homogenous in terms of SES and ethnic background. Although the results are likely to be generalizable to a Scandinavian and WesternEuropean setting, more caution must be pain when interpreting the results within a more global context. We only included survivors of working age at diagnosis (20-65 years) given the main outcomes of interest in the SWEET study. Inclusion of the oldest age groups may have further underlined the importance of increasing age as a risk factor for poor $\mathrm{HL}$, and should be further explored in upcoming studies.

Causal inference is not possible given the cross sectional design of this study. Data on $\mathrm{HL}$ is based on self-report, and reflect present skills. Although validated in the Norwegian population and for Norwegians with diabetes type II [20,43], the HLS-Q12 it has not been extensively used. Furthermore, categorization of $\mathrm{HL}$ is empirically based, and threshold values will vary. Consequently we chose to use $\mathrm{HL}$ as a continuous variable for the regression analyses. The HLS-Q47 allows for the opportunity to measure HL across three health care settings. This procedure has not been described for the HLS-Q12 as of yet. Still, the HLS-Q12 is reported to be a valid, quick and easy-to-use tool to measure $\mathrm{HL}$ in a clinical setting.

\section{Conclusions}

Within this nation-wide cohort of long-term BCSs, one in five report HL levels within the marginal or inadequate range. Despite high SES, HL-tasks specifically pertaining to advanced judgment calls were rated as difficult or very difficult by $35-41 \%$. This study demonstrate that the presence of basic HL does not automatically imply more advanced skills, which are likely to be the most crucial with regards to longterm survivorship. Survivors with higher age, neurotic personality traits and reports of FCR may warrant specific attention from health care providers. It needs to be recognized that $\mathrm{HL}$ is likely to vary with context and functional demands, and identification of individuals at risk of low HL based on objective markers alone is insufficient.

\section{Declarations}

Funding: this study was funded by the Pink Ribbon Movement and Norwegian Breast Cancer Society through grant nr 197255.

Competing interests: The authors have no relevant financial or non-financial interests to disclose.

Availability of data: all data are available at Oslo University Hospital 
Code availability: not applicable

Author contributions: KVR and KV were in charge of research design and data collection. KV, KVR and CEK designed this sub-study, KV performed all statistical analysis together with HCL. All authors contributed through the entire process including interpretation

Ethical approval: This study was performed in line with the principles of the Declaration of Helsinki. Approval was granted by the Regional Committee for Medical Research Ethics (2018/2170), the Norwegian Cancer Registry and the Data Protection Officer at Oslo University Hospital.

Informed consent to participate: Informed consent was obtained from all participants included in the study.

Consent for publication: not applicable

\section{References}

1. Sørensen K, Van den Broucke S, Fullam J, Doyle G, Pelikan J, Slonska Z, Brand H (2012) Health literacy and public health: a systematic review and integration of definitions and models. BMC Public Health 12:80

2. Berkman ND, Sheridan SL, Donahue KE, Halpern DJ, Crotty K (2011) Low health literacy and health outcomes: an updated systematic review. Ann Intern Med 155(2):97-107

3. Kickbusch IPJ, Apfel F et al (2013) : Health literacy: the solid facts. Europe: World Health Organization. 2013.

4. Bailey SC, Brega AG, Crutchfield TM, Elasy T, Herr H, Kaphingst K, Karter AJ, Moreland-Russell S, Osborn CY, Pignone M et al (2014) Update on health literacy and diabetes. Diabetes Educ 40(5):581604

5. Muellers KA, Chen L, O'Conor R, Wolf MS, Federman AD, Wisnivesky JP (2019) Health Literacy and Medication Adherence in COPD Patients: When Caregiver Presence Is Not Sufficient. Copd 16(56):362-367

6. Sørensen K, Pelikan JM, Röthlin F, Ganahl K, Slonska Z, Doyle G, Fullam J, Kondilis B, Agrafiotis D, Uiters $E$ et al (2015) Health literacy in Europe: comparative results of the European health literacy survey (HLS-EU). Eur J Pub Health 25(6):1053-1058

7. Koay K, Schofield P, Jefford M (2012) Importance of health literacy in oncology. Asia-Pac J Clin Oncol 8(1):14-23

8. Kieffer Campbell J (2020) Health Literacy in Adult Oncology: An Integrative Review. Oncol Nurs Forum 47(1):18-32

9. Barlow J, Wright C, Sheasby J, Turner A, Hainsworth J (2002) Self-management approaches for people with chronic conditions: a review. Patient Educ Couns 48(2):177-187 
10. Mackey LM, Doody C, Werner EL, Fullen B (2016) : Self-Management Skills in Chronic Disease Management: What Role Does Health Literacy Have? Medical decision making: an international journal of the Society for Medical Decision Making 36(6):741-759

11. Eton DT, Anderson RT, Cohn WF, Kennedy EM, St Sauver JL, Bucknell BJ, Ruddy KJ (2019) Risk factors for poor health-related quality of life in cancer survivors with multiple chronic conditions: exploring the role of treatment burden as a mediator. Patient related outcome measures 10:89-99

12. Clarke N, Dunne S, Coffey L, Sharp L, Desmond D, O'Conner J, O'Sullivan E, Timon C, Cullen C, Gallagher P (2021) : Health literacy impacts self-management, quality of life and fear of recurrence in head and neck cancer survivors. Journal of cancer survivorship: research and practice

13. Cancer in Norway 2019. Cancer incidence, mortality, survival and prevalence in Norway

14. Joly F, Lange M, Dos Santos M, Vaz-Luis I, Di Meglio A (2019) : Long-Term Fatigue and Cognitive Disorders in Breast Cancer Survivors. Cancers11(12)

15. Rietman JS, Dijkstra PU, Hoekstra HJ, Eisma WH, Szabo BG, Groothoff JW, Geertzen JH (2003) Late morbidity after treatment of breast cancer in relation to daily activities and quality of life: a systematic review. European journal of surgical oncology: the journal of the European Society of Surgical Oncology and the British Association of Surgical Oncology 29(3):229-238

16. Halbach SM, Enders A, Kowalski C, Pförtner TK, Pfaff H, Wesselmann S, Ernstmann N (2016) Health literacy and fear of cancer progression in elderly women newly diagnosed with breast cancer--A longitudinal analysis. Patient Educ Couns 99(5):855-862

17. Rakhshkhorshid M, Navaee M, Nouri N, Safarzaii F (2018) The Association of Health Literacy with Breast Cancer Knowledge, Perception and Screening Behavior. European journal of breast health 14(3):144-147

18. Halbach SM, Ernstmann N, Kowalski C, Pfaff H, Pförtner TK, Wesselmann S, Enders A (2016) Unmet information needs and limited health literacy in newly diagnosed breast cancer patients over the course of cancer treatment. Patient Educ Couns 99(9):1511-1518

19. Larsen IK, Småstuen M, Johannesen TB, Langmark F, Parkin DM, Bray F, Møller B (2009) Data quality at the Cancer Registry of Norway: an overview of comparability, completeness, validity and timeliness. European journal of cancer (Oxford, England: 1990) 45(7):1218-1231

20. Finbråten HS, Wilde-Larsson B, Nordström G, Pettersen KS, Trollvik A, Guttersrud Ø (2018) Establishing the HLS-Q12 short version of the European Health Literacy Survey Questionnaire: Iatent trait analyses applying Rasch modelling and confirmatory factor analysis. BMC Health Serv Res 18(1):506

21. Guttersrud $\varnothing$, Pettersen KS, Finbråten HS (2019) : Measuring health literacy using HLS-NO-Q12: Empirically identifying and describing cumulative benchmarks for statistically different levels of performance. In: The 4th European Health Literacy Conference, Dublin.

22. Armitage JN, van der Meulen JH (2010) Identifying co-morbidity in surgical patients using administrative data with the Royal College of Surgeons Charlson Score. Br J Surg 97(5):772-781 
23. Brusselaers N, Lagergren J (2017) The Charlson Comorbidity Index in Registry-based Research. Methods Inf Med 56(5):401-406

24. Grav S, Stordal E, Romild UK, Hellzen O (2012) The relationship among neuroticism, extraversion, and depression in the HUNT Study: in relation to age and gender. Issues Ment Health Nurs 33(11):777785

25. Aaronson NK, Ahmedzai S, Bergman B, Bullinger M, Cull A, Duez NJ, Filiberti A, Flechtner H, Fleishman SB, de Haes JC et al (1993) The European Organization for Research and Treatment of Cancer QLQ-C30: a quality-of-life instrument for use in international clinical trials in oncology. J Natl Cancer Inst 85(5):365-376

26. Oldenburg J, Fosså SD, Dahl AA (2006) Scale for chemotherapy-induced long-term neurotoxicity (SCIN): psychometrics, validation, and findings in a large sample of testicular cancer survivors. Quality of life research: an international journal of quality of life aspects of treatment, care and rehabilitation 15(5):791-800

27. Sprangers MA, Groenvold M, Arraras JI, Franklin J, te Velde A, Muller M, Franzini L, Williams A, de Haes HC, Hopwood P et al (1996) The European Organization for Research and Treatment of Cancer breast cancer-specific quality-of-life questionnaire module: first results from a three-country field study. Journal of clinical oncology: official journal of the American Society of Clinical Oncology 14(10):2756-2768

28. Chalder T, Berelowitz G, Pawlikowska T, Watts L, Wessely S, Wright D, Wallace EP (1993) Development of a fatigue scale. J Psychosom Res 37(2):147-153

29. Krokstad S, Langhammer A, Hveem K, Holmen TL, Midthjell K, Stene TR, Bratberg G, Heggland J, Holmen J (2013) Cohort Profile: the HUNT Study, Norway. Int J Epidemiol 42(4):968-977

30. Kroenke K, Spitzer RL, Williams JB (2001) The PHQ-9: validity of a brief depression severity measure. J Gen Intern Med 16(9):606-613

31. Spitzer RL, Kroenke K, Williams JB, Löwe B (2006) : A brief measure for assessing generalized anxiety disorder. the GAD-7. Archives of internal medicine 166(10):1092-1097

32. Thewes B, Zachariae R, Christensen S, Nielsen T, Butow P (2015) The Concerns About Recurrence Questionnaire: validation of a brief measure of fear of cancer recurrence amongst Danish and Australian breast cancer survivors. Journal of cancer survivorship: research and practice 9(1):68-79

33. Heijmans M, Waverijn G, Rademakers J, van der Vaart R, Rijken M (2015) : Functional, communicative and critical health literacy of chronic disease patients and their importance for selfmanagement. Patient education and counseling 98(1):41-48

34. Lebel S, Ozakinci G, Humphris G, Mutsaers B, Thewes B, Prins J, Dinkel A, Butow P (2016) From normal response to clinical problem: definition and clinical features of fear of cancer recurrence. Supportive care in cancer: official journal of the Multinational Association of Supportive Care in Cancer 24(8):3265-3268

35. Simard S, Thewes B, Humphris G, Dixon M, Hayden C, Mireskandari S, Ozakinci G (2013) Fear of cancer recurrence in adult cancer survivors: a systematic review of quantitative studies. Journal of 
cancer survivorship: research and practice 7(3):300-322

36. Vandraas KF, Reinertsen KV, Kiserud CE, Lie HC (2020) : Fear of cancer recurrence among young adult cancer survivors-exploring long-term contributing factors in a large, population-based cohort. Journal of cancer survivorship: research and practice

37. Verkissen MN, Ezendam NPM, Fransen MP, Essink-Bot M-L, Aarts MJ, Nicolaije KAH, Vos MC, Husson $\mathrm{O}$ (2014) The role of health literacy in perceived information provision and satisfaction among women with ovarian tumors: A study from the population-based PROFILES registry. Patient Educ Couns 95(3):421-428

38. Dahl AA (2010) Link between personality and cancer. Future oncology (London, England) 6(5):691707

39. Novak JR, Anderson JR, Johnson MD, Hardy NR, Walker A, Wilcox A, Lewis VL, Robbins DC (2017) Does Personality Matter in Diabetes Adherence? Exploring the Pathways between Neuroticism and Patient Adherence in Couples with Type 2 Diabetes. Applied psychology Health and well-being 9(2):207-227

40. Kim HZQ, Svynarenko R (2017) Personality traits and health literacy. J Family Med Community Health 4(1):1102

41. Bøhn SH, Lie HC, Reinertsen KV, Fosså SD, Haugnes HS, Kiserud CE, Loge JH, Wisløff T, Thorsen L (2021) Lifestyle among long-term survivors of cancers in young adulthood. Supportive care in cancer: official journal of the Multinational Association of Supportive Care in Cancer 29(1):289-300

42. Lie HC, Rueegg CS, Fossa SD, Loge JH, Ruud E, Kiserud CE (2019) Limited evidence of non-response bias despite modest response rate in a nationwide survey of long-term cancer survivors-results from the NOR-CAYACS study. Journal of cancer survivorship: research and practice 13(3):353-363

43. Finbråten HS, Pettersen KS, Wilde-Larsson B, Nordström G, Trollvik A, Guttersrud $\varnothing$ (2017) Validating the European Health Literacy Survey Questionnaire in people with type 2 diabetes: Latent trait analyses applying multidimensional Rasch modelling and confirmatory factor analysis. J Adv Nurs 73(11):2730-2744

\section{Tables}

Table I: Description of study sample $(n=1355)$ for categorical $(n(\%)$, and continuous variables (mean, SD and median, range) 


\begin{tabular}{|c|c|}
\hline Categorical variables & $\mathrm{n}(\%)$ \\
\hline \multicolumn{2}{|l|}{ Socio-demographic variables } \\
\hline Education $\leq 12 \mathrm{y}$ & $647(47.7)$ \\
\hline Education $>12$ y & $691(51.0)$ \\
\hline \multirow{2}{*}{$\begin{array}{l}-\leq 4 \text { years higher education } \\
\text { - }>4 \text { years higher education }\end{array}$} & $290(21.4)$ \\
\hline & 401 (29.6) \\
\hline High household income ${ }_{a}$ & $923(68.1)$ \\
\hline Living with partner or children & $1079(79.6)$ \\
\hline Employment $_{\mathrm{b}}$ & $1035(76.4)$ \\
\hline \multicolumn{2}{|l|}{ Clinical variables } \\
\hline \multicolumn{2}{|l|}{ Receptor expression } \\
\hline \multicolumn{2}{|l|}{ - Hormone receptor positive } \\
\hline \multicolumn{2}{|l|}{ - HER-2 positive } \\
\hline \multicolumn{2}{|l|}{ - Triple negative (TNBC) } \\
\hline \multicolumn{2}{|l|}{ Stage $(\mathrm{TNM})_{\mathrm{C}}$} \\
\hline I & $606(44.7)$ \\
\hline$\|$ & $486(35.9)$ \\
\hline III & $108(8.0)$ \\
\hline \multicolumn{2}{|l|}{ Surgery $_{d}$} \\
\hline \multirow{2}{*}{$\begin{array}{l}\text { - Mastectomy } \\
\text { - Breast conserving therapy }\end{array}$} & $559(41.3)$ \\
\hline & $788(58.2)$ \\
\hline Chemotherapy, all regimens & $926(68.3)$ \\
\hline Radiotherapy, all regimens & $1087(80.2)$ \\
\hline Endocrine therapy, all regimens & $881(65.0)$ \\
\hline Herceptin & $242(17.9)$ \\
\hline \multicolumn{2}{|l|}{ Physical health } \\
\hline Comorbidity & \\
\hline
\end{tabular}




\begin{tabular}{|c|c|c|}
\hline - $1-2$ conditions & $731(53.9)$ & \\
\hline - $>2$ conditions & $326(24.1)$ & \\
\hline High degree of neuropathy & $277(20.4)$ & \\
\hline Sleep problems $_{e}$ & $59.2(43.7)$ & \\
\hline Continous variables & Mean (SD) & Median (range) \\
\hline Age at survey (years) & $59.9(8.7)$ & $60.0(30-74)$ \\
\hline Age at diagnosis (years) & $51.9(8.6)$ & $52.0(21-65)$ \\
\hline Neuroticism $_{f}$ & $2.17(1.9)$ & $2.0(0-6)$ \\
\hline Cognitive function $_{\mathrm{g}}$ & $74.3(24.9)$ & $83.3(0-100)$ \\
\hline Arm symptoms $s_{f}$ & $20.7(24.6)$ & $11.1(0-100)$ \\
\hline Breast symptoms $s_{f}$ & $16.2(19.3)$ & $8.3(0-100)$ \\
\hline Pain $_{f}$ & $28.1(29.4)$ & $16.7(0-100)$ \\
\hline PHQ-9 depressive symptoms ${ }_{f}$ & $5.9(4.5)$ & $5.0(0-27)$ \\
\hline GAD-7 anxiety symptoms $s_{f}$ & $3.8(3.6)$ & $3.0(0-21)$ \\
\hline Fear of cancer recurrence $_{f}$ & $11.7(8.7)$ & $9.0(0-40)$ \\
\hline Fatigue $_{f}$ & $14.8(5.8)$ & $13.0(0-33)$ \\
\hline
\end{tabular}

a $\geq 500000 \mathrm{NOK} /$ year equal to $48000 €$ /year, bemployed= paid work; full time, part time, on sick leave, self-employed and freelance. ${ }_{c} n=1200$ due to missing values for $11.4 \%$. ${ }^{n} n=1347$ due to missing values

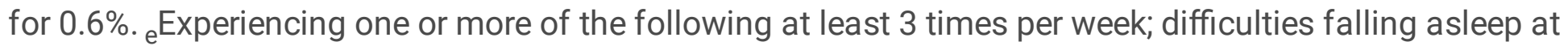
night and/or waking up too early without being able to go back to sleep fincreasing score=increasing symptoms. $g$ Increasing score = increasing function.

Table II. Frequencies ( $n, \%)$ of responses for each item of the HLS-Q12, corresponding HLS Q47 items, HL sum scores before and after imputation (mean and SD) and categorized HL levels 


$\begin{array}{lllllll}\text { n: } & \text { Item in } & \text { Very } & \text { Difficult } & \text { Easy } & \begin{array}{l}\text { Very } \\ \text { easy }\end{array} & \begin{array}{l}\text { Don't } \\ \text { know }\end{array} \\ \begin{array}{lll}\text { (\%) } & \text { HLSQ47 } & \text { difficult }\end{array} & & & & & \end{array}$

On a scale from very difficult to very easy, how easy would you say it is to:

find information on
treatments of illnesses that
concern you?

understand what to do in a

medical emergency?

judge the advantages and disadvantages of different treatment options?

follow the instructions on

medication?

find information on how to

manage mental health

problems like stress or

depression?

understand why you need
health screenings?
judge if the information on
health risks in the media is
reliable?

decide how you can protect

yourself from illness based

on advice from family and

friends?

find information on healthy

activities, such as exercise,

healthy food and nutrition?

understand information on

food packaging?

judge which everyday

behaviour is related to your health?

make decisions to improve

your health?

HL categorized

n (\%)

(97.6)

1320

(97.4)

(97.4)

1326
21

$\begin{array}{ll}1324 & 2 \\ (97.7) & \end{array}$

$1311 \quad 7$

(96.8)

$1247 \quad 10$

(92.0)

$1323 \quad 14$

(97.6)

$1319 \quad 18$

(97.3)

25

25

(1.8) (21.2)

53

(3.9)

504

(37.2)

198
$(14.6)$

744

(54.9)

214

(15.8)

147

(10.8)

1.5)

(3.9)

$3(0.2)$

49 (3.6)

742

(54.8)

26

(1.9)

299

(22.1)

592

(43.7)

664
$(49.0)$

200

(14.8)

135

(10.0)

$455 \quad 99$

136

(33.6)

(7.3)

(10.0)

29

240

$\begin{array}{lllllll}\begin{array}{l}1331 \\ (98.2)\end{array} & 23 & 2(0.1) & 32(2.4) & \begin{array}{l}635 \\ (46.9)\end{array} & \begin{array}{l}636 \\ (46.9)\end{array} & \begin{array}{l}26 \\ (1.9)\end{array} \\ \begin{array}{lllllll}1303 \\ (96.2)\end{array} & 28 & \begin{array}{l}47 \\ (3.5)\end{array} & \begin{array}{l}431 \\ (31.8)\end{array} & \begin{array}{l}535 \\ (39.5)\end{array} & \begin{array}{l}157 \\ (11.6)\end{array} & \begin{array}{l}133 \\ (9.8)\end{array} \\ & & & & & & \\ 1308 & 30 & 49 & 333 & 522 & 157 & 247 \\ (96.5) & & (3.6) & (24.6) & (38.5) & (11.6) & (18.2)\end{array}$

$1322 \quad 32$

$8(0.6)$

$69(5.1)$

748

478

19

32

(55.2)

(35.3)

38

14

(1.0)

221

(16.3)

703

347

(51.9) (25.6)

35

$1320 \quad 43$

$7(0.5)$

135
$(10.0)$

742

(54.8)

412

(30.4)

24

44

23

(1.7)

324

(23.9)

682

275

(50.3) (20.3)

22

(1.6)

- Inadequate 


\begin{tabular}{|l|l|}
\hline & 231 \\
& $(17.0)$ \\
\hline & 528 \\
- Mntermediate & $(39.0)$ \\
\hline - Advanced & 328 \\
\hline Total & $(24.2)$ \\
& 1118 \\
& $(82.5)_{a}$ \\
& Mean \\
& $($ SD) \\
\hline HL sum score, prior to & 36.4 \\
imputation & $(5.5)$ \\
\hline HL sum score, after & 36.2 \\
imputation & $(5.4)$ \\
\hline
\end{tabular}

a missing values (non-responders and “don't know” responses): 237 (17.5\%)

Table III: Univariate linear regression analysis with health literacy sum score as dependent variable 


\begin{tabular}{|c|c|c|c|c|c|}
\hline & $\begin{array}{l}\text { Unstandardized } \\
\text { coefficient }\end{array}$ & $\begin{array}{l}\text { Standardized } \\
\text { coefficient }\end{array}$ & Sig.a $_{a}$ & $\begin{array}{l}95 \% \mathrm{Cl}_{b} \\
\text { for B }\end{array}$ & \\
\hline & & & & $\begin{array}{l}\text { Lower } \\
\text { Bound }\end{array}$ & $\begin{array}{l}\text { Upper } \\
\text { Bound }\end{array}$ \\
\hline Education $_{\mathrm{c}}$ & 1.09 & 0.08 & 0.02 & 0.22 & 1.96 \\
\hline $\begin{array}{l}>4 \text { y.higher } \\
\text { education }\end{array}$ & 2.43 & 0.21 & 0.00 & 1.67 & 3.20 \\
\hline Household income $_{c}$ & 2.21 & 0.19 & 0.00 & 1.47 & 2.94 \\
\hline $\begin{array}{l}\text { Living with } \\
\text { partner/children } \\
d\end{array}$ & -0.34 & -0.03 & 0.44 & -1.21 & 0.53 \\
\hline Age at survey & -0.07 & -0.11 & 0.00 & -0.11 & -0.03 \\
\hline Employment $_{d}$ & -1.16 & -0.09 & 0.01 & -1.99 & -0.33 \\
\hline Age at diagnosis & -0.07 & -0.11 & 0.00 & -0.11 & -0.03 \\
\hline $\begin{array}{l}\text { Hormone receptor } \\
\text { positivity }_{d}\end{array}$ & -1.21 & -0.08 & 0.01 & -2.17 & -0.24 \\
\hline TNM stage 2 vs 1 & -0.59 & -0.05 & 0.11 & -1.32 & 0.14 \\
\hline TNM stage 3 vs 1 & -0.40 & -0.02 & 0.54 & -1.65 & 0.86 \\
\hline $\mathrm{TNBC}_{\mathrm{d}}$ & 0.80 & 0.04 & 0.20 & -0.41 & 2.02 \\
\hline Surgery $_{d}$ & -0.36 & -0.03 & 0.30 & -1.05 & 0.33 \\
\hline Chemotherapy $_{d}$ & 0.49 & 0.04 & 0.20 & -0.26 & 1.24 \\
\hline Radiotherapy $_{d}$ & -0.43 & -0.03 & 0.32 & -1.28 & 0.41 \\
\hline Endocrine therapy $_{d}$ & -0.22 & -0.02 & 0.56 & -0.96 & 0.52 \\
\hline Herceptin $_{d}$ & 0.59 & 0.04 & 0.20 & -0.31 & 1.49 \\
\hline $\begin{array}{l}1-2 \text { comorbid } \\
\text { conditions }_{d}\end{array}$ & -1.00 & -0.09 & 0.02 & -1.86 & -0.14 \\
\hline $\begin{array}{l}>2 \text { comorbid } \\
\text { conditions }_{d}\end{array}$ & -1.48 & -0.12 & 0.00 & -2.47 & -0.48 \\
\hline Pain $_{e}$ & -0.02 & -0.11 & 0.00 & -0.03 & -0.01 \\
\hline Cognitiv function $_{f}$ & 0.03 & 0.16 & 0.00 & 0.02 & 0.05 \\
\hline
\end{tabular}




\begin{tabular}{|c|c|c|c|c|c|}
\hline Breast symptoms $\mathrm{e}_{\mathrm{e}}$ & -0.04 & -0.13 & 0.00 & -0.06 & -0.02 \\
\hline Arm symptoms ${ }_{\mathrm{e}}$ & -0.03 & -0.14 & 0.00 & -0.04 & -0.02 \\
\hline Neuropathy $_{c}$ & -0.87 & -0.07 & 0.04 & -1.69 & -0.04 \\
\hline Sleep problems $s_{d}$ & -0.67 & -0.06 & 0.06 & -1.37 & 0.03 \\
\hline Fatigue $_{e}$ & -0.11 & -0.12 & 0.00 & -0.17 & -0.05 \\
\hline $\begin{array}{l}\text { Depressive } \\
\text { symptoms }_{e}\end{array}$ & -0.21 & -0.18 & 0.00 & -0.28 & -0.13 \\
\hline Anxiety symptoms ${ }_{e}$ & -0.32 & -0.21 & 0.00 & -0.41 & -0.22 \\
\hline $\begin{array}{l}\text { Fear of cancer } \\
\text { recurrence }_{e}\end{array}$ & -0.15 & -0.23 & 0.00 & -0.18 & -0.11 \\
\hline Neuroticism $_{e}$ & -0.67 & -0.24 & 0.00 & -0.85 & -0.50 \\
\hline
\end{tabular}

${ }_{a}$ Significance level, ${ }_{b}$ confidence interval, $c$ reference low, dreference not, $\mathrm{e}$ higher score implies worse symptoms, fhigher score implies better function. Bold: Statistically significant $(p<.05)$ associated with $\mathrm{HL}$

Table IV: Multivariate linear regression analysis with health literacy sum score as dependent variable 


\begin{tabular}{|c|c|c|c|c|c|}
\hline $\mathrm{N}: 940$ & $\begin{array}{l}\text { Unstandardized } \\
\text { Coefficients }\end{array}$ & $\mathrm{SE}_{\mathrm{a}}$ & $\begin{array}{l}\text { Standardized } \\
\text { Coefficients }\end{array}$ & $\begin{array}{l}\text { Sig.b } \\
\mathrm{R}^{2}\end{array}$ & $\mathrm{R}_{\text {adj }}$ \\
\hline & B & & Beta & 0.14 & 0.12 \\
\hline Education $_{\mathrm{c}}$ & 0.55 & 0.44 & 0.04 & 0.21 & \\
\hline $\begin{array}{l}>4 \text { y.higher } \\
\text { education }\end{array}$ & 1.32 & 0.41 & 0.12 & 0.00 & \\
\hline Household income $_{c}$ & 1.11 & 0.40 & 0.10 & 0.01 & \\
\hline Employment $_{d}$ & 0.17 & 0.41 & 0.02 & 0.68 & \\
\hline Age at diagnosis & -0.08 & 0.03 & -0.13 & 0.00 & \\
\hline $\begin{array}{l}\text { Hormone receptor } \\
\text { positivity }_{d}\end{array}$ & -0.72 & 0.47 & -0.05 & 0.13 & \\
\hline $\begin{array}{l}1-2 \text { comorbid } \\
\text { conditions }_{d}\end{array}$ & -0.16 & 0.44 & -0.02 & 0.72 & \\
\hline $\begin{array}{l}>2 \text { comorbid } \\
\text { conditions }_{d}\end{array}$ & 0.17 & 0.56 & 0.01 & 0.76 & \\
\hline Pain $_{e}$ & 0.01 & 0.01 & 0.06 & 0.18 & \\
\hline${\text { Cognitiv } \text { function }_{f}}$ & 0.02 & 0.01 & 0.08 & 0.08 & \\
\hline Breast symptoms ${ }_{e}$ & 0.00 & 0.01 & -0.01 & 0.89 & \\
\hline Arm symptoms ${ }_{e}$ & -0.02 & 0.01 & -0.07 & 0.08 & \\
\hline Neuropathy $_{c}$ & 0.06 & 0.44 & 0.00 & 0.90 & \\
\hline Sleep problems $s_{d}$ & 0.44 & 0.37 & 0.04 & 0.24 & \\
\hline Fatigue $_{\mathrm{e}}$ & 0.01 & 0.04 & 0.02 & 0.74 & \\
\hline $\begin{array}{l}\text { Depressive } \\
\text { symptoms }_{e}\end{array}$ & -0.01 & 0.07 & -0.01 & 0.84 & \\
\hline Anxiety symptoms $\mathrm{e}_{\mathrm{e}}$ & -0.12 & 0.08 & -0.08 & 0.12 & \\
\hline $\begin{array}{l}\text { Fear of cancer } \\
\text { recurrence }_{e}\end{array}$ & -0.08 & 0.02 & -0.13 & 0.00 & \\
\hline Neuroticism $_{e}$ & -0.27 & 0.13 & -0.10 & 0.03 & \\
\hline
\end{tabular}


astandard error. ${ }_{b}$ significance level ${ }_{c}$ reference low, dreference not, ehigher score implies worse symptoms, fhigher score implies better function. Bold: Statistically significant $(p<.05)$ associated with $\mathrm{HL}$ 